\title{
ОРГАНИЗАЦИЯ ПОМОЩИ БОЛЬНЫМ С ИНСУЛЬТАМИ
}

\author{
*С.У. Каменова, А.М.Кондыбаева, О.А. Остапенко, Е. Белая \\ КазНМУ им. С.Д. Асфендиярова, Алматы, Казахстан
}

Анализ проблемы сосудистых заболеваний мозга требует оценки организации помощи больным на ранних этапах. Лечебная коррекция выявленных ранних сосудистых синдромов может быть весьма эффективной и способна существенно снизить заболеваемость инсультом при своевременной диагностике и оказании квалифицированной помощи. В статье представлены эпидемиологические данные по г. Алматы и Атырауской области.

Ключевые слова: инсульт, экстренная помощь, компьютерная томография, госпитальный этап, распространенность, смертность, летальность.

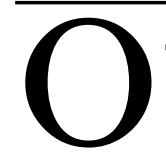
дной из приоритетных задач Государственной программы развития здравоохранения Республики Казахстан "Саламатты Казахстан" на 2011-2015 годы является переход на международные принципы организации медицинской помощи населению (1).

В 2004 г. ВО3 объявила инсульт глобальной эпидемией, угрожающей жизни и здоровью населения всего мира. В соответствии с оценками ВО3 2006г. в мире ежегодно регистрируется около 6 млн. случаев мозгового инсульта, каждый четвертый из них - с летальным исходом.

Введение. В многочисленных исследованиях, проведенных, в развитых странах выявлена четкая связь между качеством организации и оказания медицинской помощи больным с инсультом и показателями смертности и инвалидизации (2).

В этой связи нами проведены исследования, касающиеся изучения эпидемиологических показателей острых нарушений мозгового кровообращения в различных регионах нашей страны, которые свидетельствуют о высоком уровне заболеваемости инсультом $(3,4,5)$. Данная работа проводилась в рамках государственной научно-технической программы: "Научные разработки в области диагностики и внедрения передовых технологий по лечению и реабилитации лиц с геморрагическим и ишемическим инсультами в структуре цереброваскулярных заболеваний", 2006 г.

В рамках Государственной программы развития здравоохранения Республики Казахстан "Саламатты Казахстан" издан приказ Министра здравоохранения Республики Казахстан от 28 октября 2011 года за №746 "Об утверждении мер по усилению ответственности респуб*e-mail: ellichka.zh@mail.ru ликанских организаций по снижению смертности от болезней системы кровообращения"

Одной из задач этой программы стало создание Региональных инсультных центров, оказывающих специализированную помощь больным с сосудистыми заболеваниями мозга и расширение нейроинсультных отделений на базе действующих лечебно-диагностических учреждений; укрепление их материально-технической и научной баз; повышение доступности и качества оказания медицинской помощи всем категориям больных, страдающих сосудистыми заболеваниями головного мозга. Приказ Министра здравоохранения Республики Казахстан от июня 2011 г. "О создании Региональных инсультных центров".

2012 г. объявлен Минздравом республики годом борьбы с инсультом, и мы видим, что положение дел здесь стало исправляться, делаются реальные шаги в этом направлении. Меры, предпринимаемые правительством и Министерством здравоохранения РК, своевременны и обоснованны. Они направлены на разработку и внедрение эффективных способов диагностики и лечения инсульта, совершенствования медицинской помощи при остром инсульте с применением высоких технологий. На сегодняшний день в Казахстане открыто 26 инсультных центров, в этом году планируется открыть еще 22 центра.

Согласно приказу Управления здравоохранения г. Алматы открыты в 2011 г. два региональных инсультных центра - на базе клинической больницы №7 "Калкаман" и один на базе БСМП, а с июля 2013 г. на базе ЦГКБ.

В мае 2012 г. на основании приказа областного Управления здравоохранения на базе Атырауской Областной больницы также от- 
крыт инсультный центр.

Материалы и методы. Специально организованные Регистры инсульта г. Алматы и Атырауской области (2006-2008 гг.) явились источником достоверной информации о заболеваемости, смертности, летальности, частоте рецидивов этого заболевания, его социальных последствиях.

Результаты наших исследований показали, что заболеваемость инсультом в различных регионах нашей страны составляет 2,5-3,7 случая на 1000 населения в год, смертность от 1 до 1,8 случаев на 1000 населения в год.

Нами выявлены различия в распространенности, заболеваемости и смертности от инсульта между популяцией г. Алматы и Атырауской области.

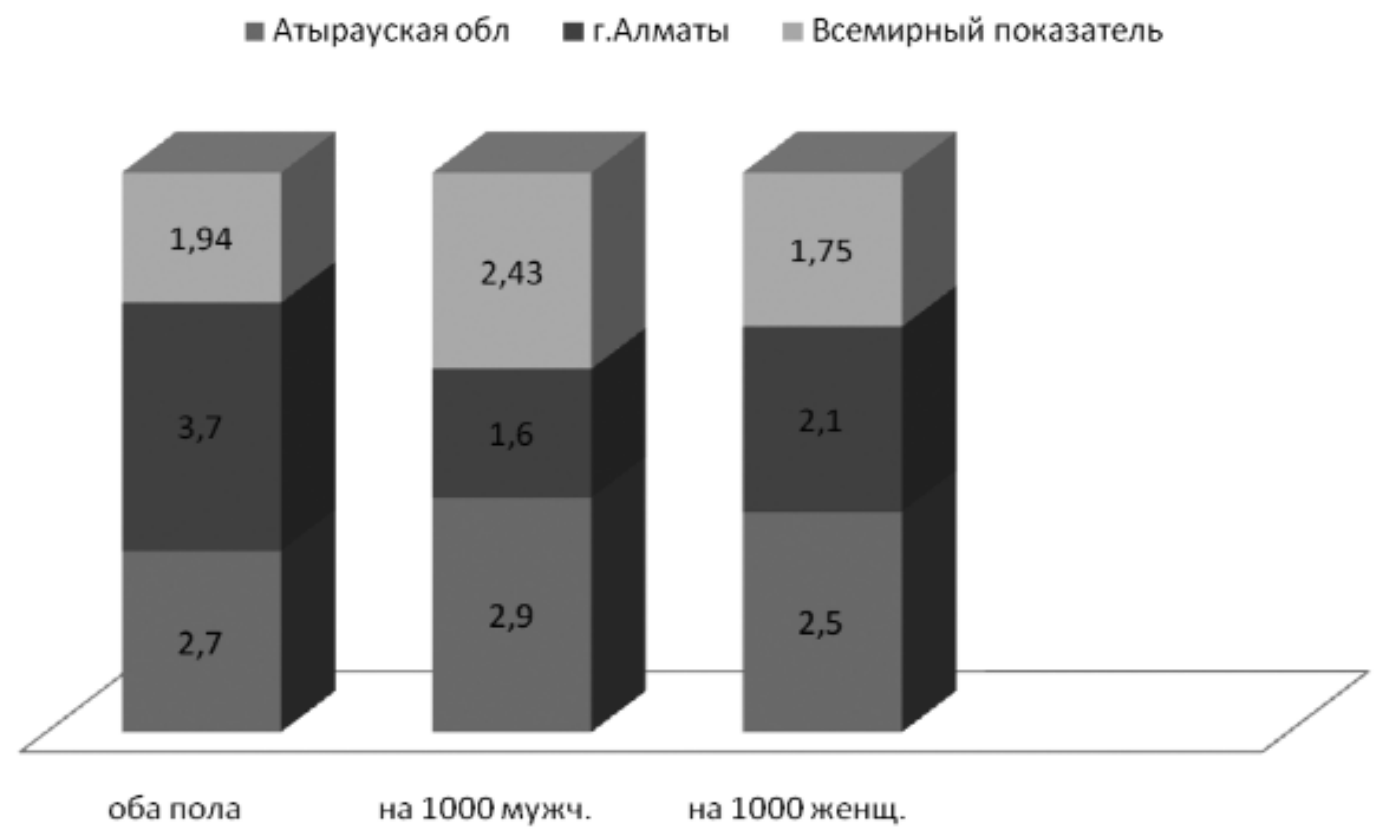

Рисунок 1. Заболеваемость инсультом в зависимости от региона на 1000 человек

Заболеваемость инсультом в г. Алматы со- у мужчин и 60-79 лет у женщин. Смертность ставила 3,7 на 1000 человек в год. Наиболее от инсульта составила 1,8 на 1000 человек в высокая заболеваемость инсультом 50-59 лет год.

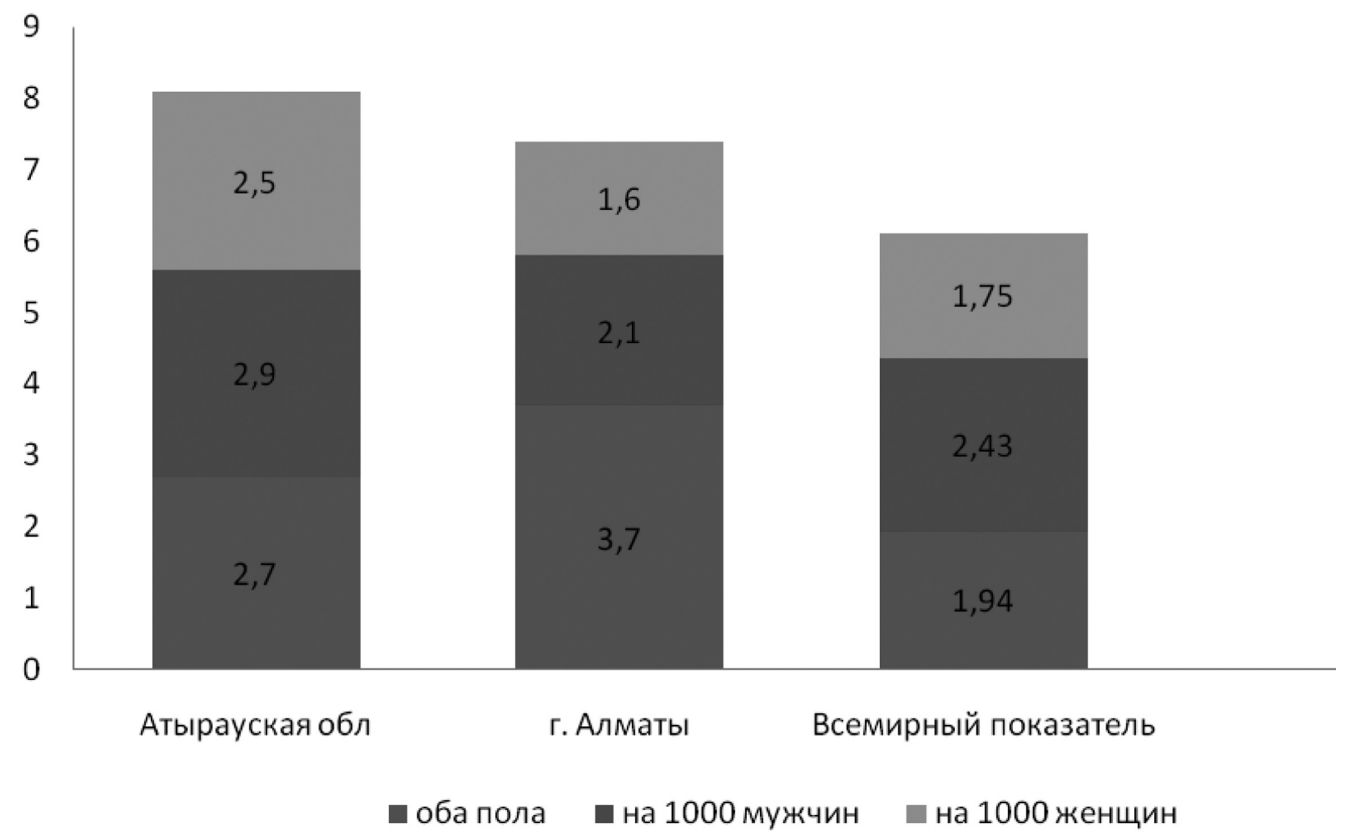

Рисунок 2 - Смертность больных от инсульта в зависимости от региона на 1000 жителей 
Заболеваемость инсультом в Атырауской области составила 2,7 на 1000 человек в год. Наиболее высокая заболеваемость инсультом выявлена в возрасте 40-59 лет у мужчин и в возрасте 50-69 лет у женщин. Смертность от инсульта составила 1,1 на 1000 человек в год.

При оценке данных регистра двух регионов заболеваемость и летальность от инсультов в г. Алматы оказалась выше, чем в Атырауской области. Это объясняется, прежде всего возрастным составом населения. В популяции г. Алматы преобладают лица старших возрастных групп. Кроме того исследования в Атырауской области проводились на базе госпитального регистра. Не все больные из области с ОНМК доставлялись в стационар, многие пациенты проходили лечение в районных больницах.

Нами проведен анализ госпитального регистра.

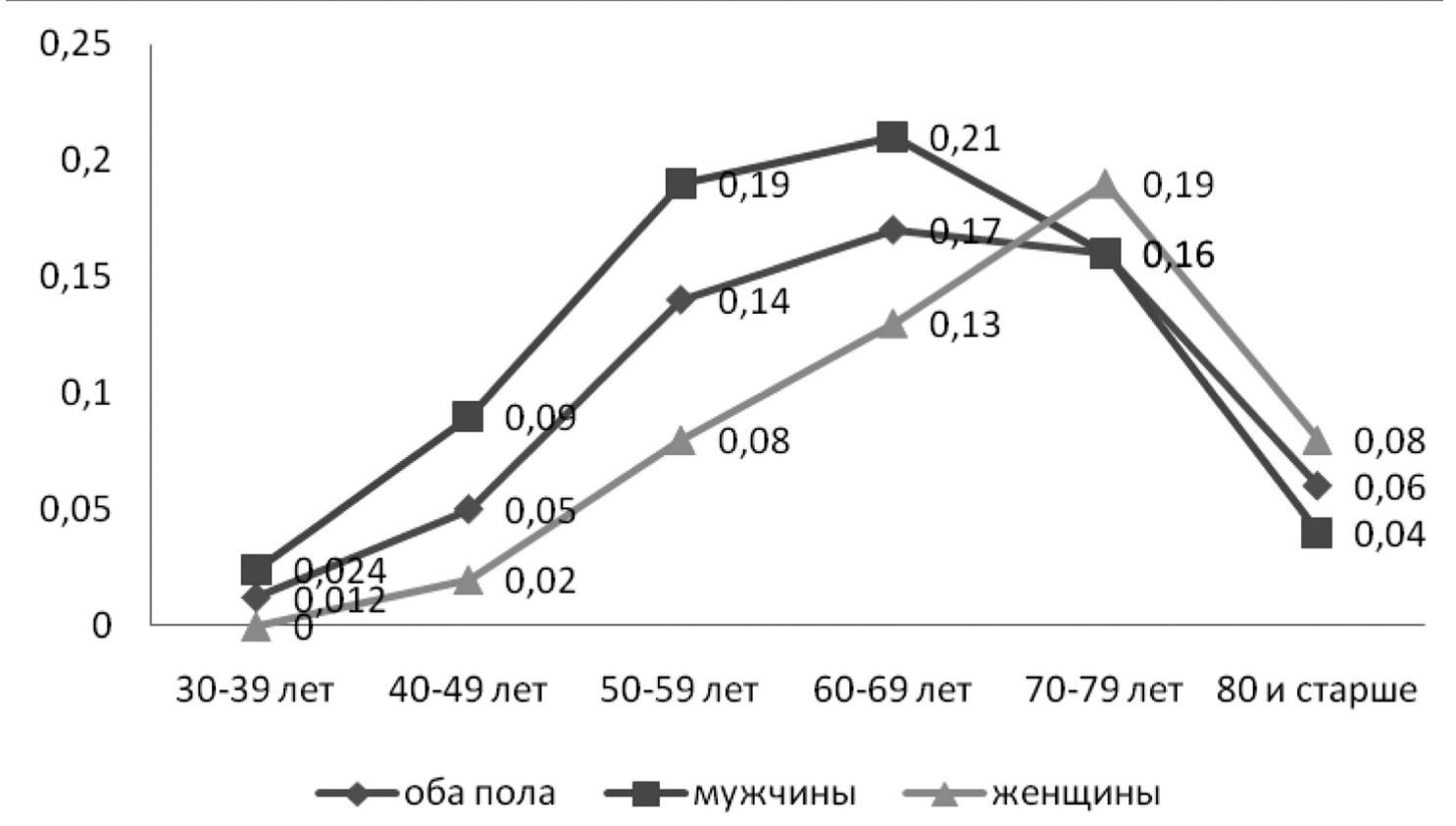

Рисунок 3. Смертность от инсульта по Атырауской области в зависимости от возраста и пола.

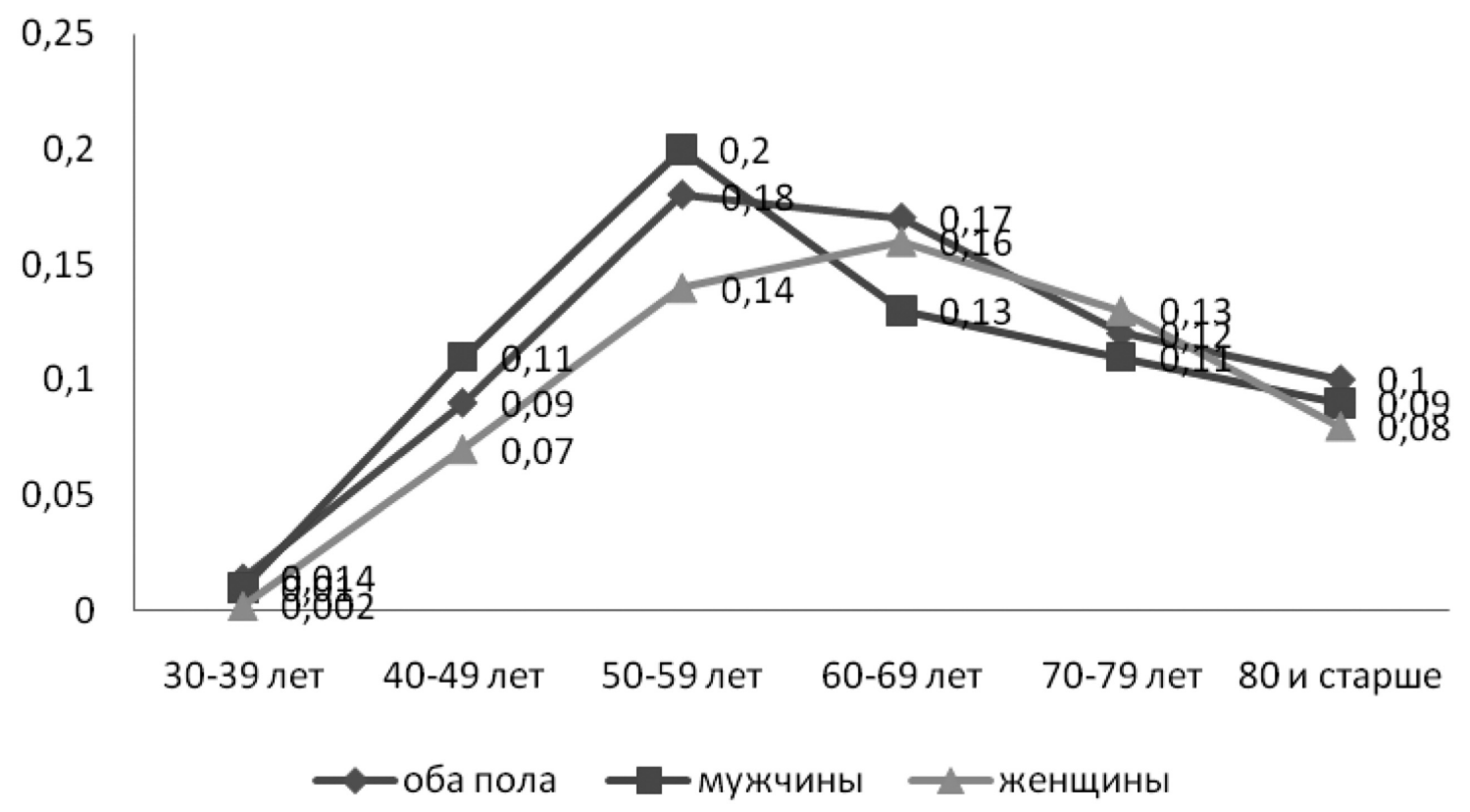

Рисунок 3. - Смертность от инсульта по г. Алматы в зависимости от возраста и пола. 
Исследование по госпитальному регистру проводилось за 2012-2013 гг. на базе инсультного центра областной г. Атырау, где проходят стационарное лечение больные с острыми нарушениями мозгового кровообращения. Инсультный центр работает в круглосуточном режиме, оказывает экстренную специализированную помощь, а также консультативную помощь жителям города и области. Здесь сформирована эффективная инсультная служба для назначения полноценного лечения и ранней реабилитации таких больных. Проводится внедрение алгоритмов и методических рекомендаций по оказанию медицинской помощи пациентам с острыми нарушениями мозгового кровообращения. Важной отличительной чертой работы центра является применение ранней реабилитации больных, начиная с первых суток силами медицинского персонала.

Проводится мониторинг всех поступивших больных, где указываются паспортные данные, пол, возраст, характер инсульта, проведение компьютерной томографии, фоновые и сопутствующие заболевания, факторы риска, летальность, сроки выживания. Возрастной диапазон группы пациентов составил от 25 до
75 и старше лет. Зарегистрировано 829 больных в 2012 г. и 835 больных в 2013 г. с инсультами, куда включались ишемические инфаркты, геморрагии, субарахноидальные кровоизлияния, ПНМК. Больным в приемном покое проводят по протоколу весь комплекс необходимых обследований. Компьютерная томография проводится всем больным, поступившим инсультный центр. Нами проанализированы сроки госпитализации от момента возникновения первых симптомов заболевания. В период "терапевтического окна" от 3 до 6 часов госпитализировано в 2012 г. 23\% больных в 2013 г госпитализировано 58\% больных. Больные из приемного покоя попадают в реанимационное отделение. Здесь имеется оснащение современными функциональными кроватями, специальными кислородными установками, также в палате есть мониторы, которые отслеживают состояние пациента. Попавший сюда больной осматривается неврологом, терапевтом, офтальмологом, реаниматологом. Далее больной переводится в отделение. В круглосуточном режиме, под постоянным контролем врачей работает палата интенсивной терапии. Затем больные переводятся в палаты.

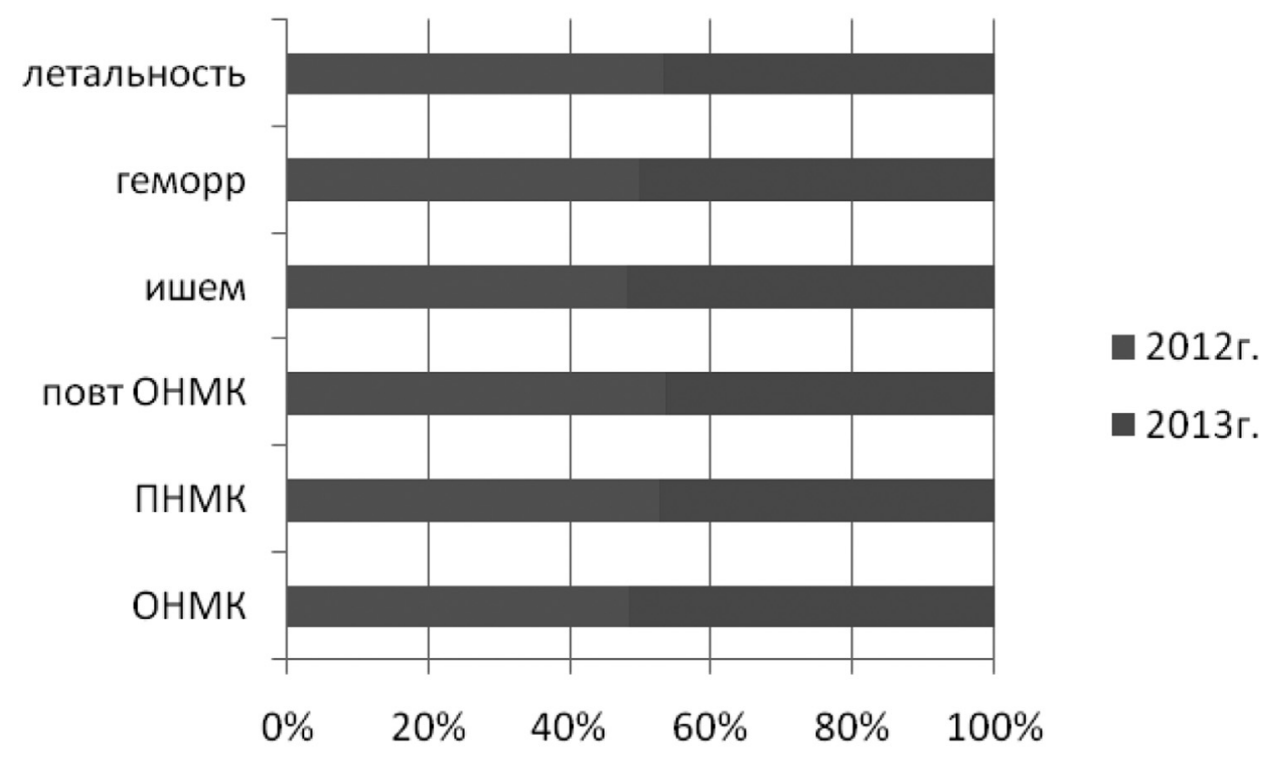

Рис. 4. Показатели работы инсультного отделения г. Атырау за 2012г-2013г

При исследовании заболеваемости отмечается достоверный рост геморрагических инсультов у мужчин, ишемических инфарктов у женщин. В структуре инсульта за 2012-2013 гг. $80 \%$ заняли ишемические инсульты и $20 \%$ геморрагические инсульты и САК. Уровень заболеваемости среди мужского населения выше, чем женского. 


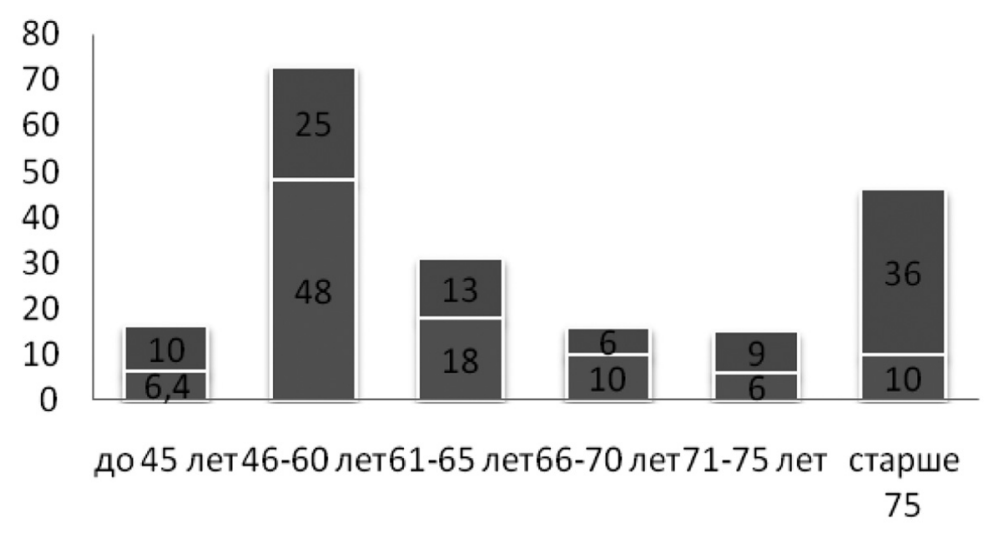

- 2012г. - 2013г.

Рис. 5. Показатели летальности инсультного отделения г. Атырау за 2012г-2013г

При исследовании летальности от инсульта в различных возрастных группах отмечается нарастание летальности к 46-65 годам. Явное увеличение летальности приходится на возраст 50-59 лет, затем на возраст старше 75 лет.
При сравнении показателей госпитальной летальности за два года наметилась тенденция к ее снижению. Основными причинами явились артериальная гипертензия, атеросклероз сосудов головного мозга, мерцательная аритмия.

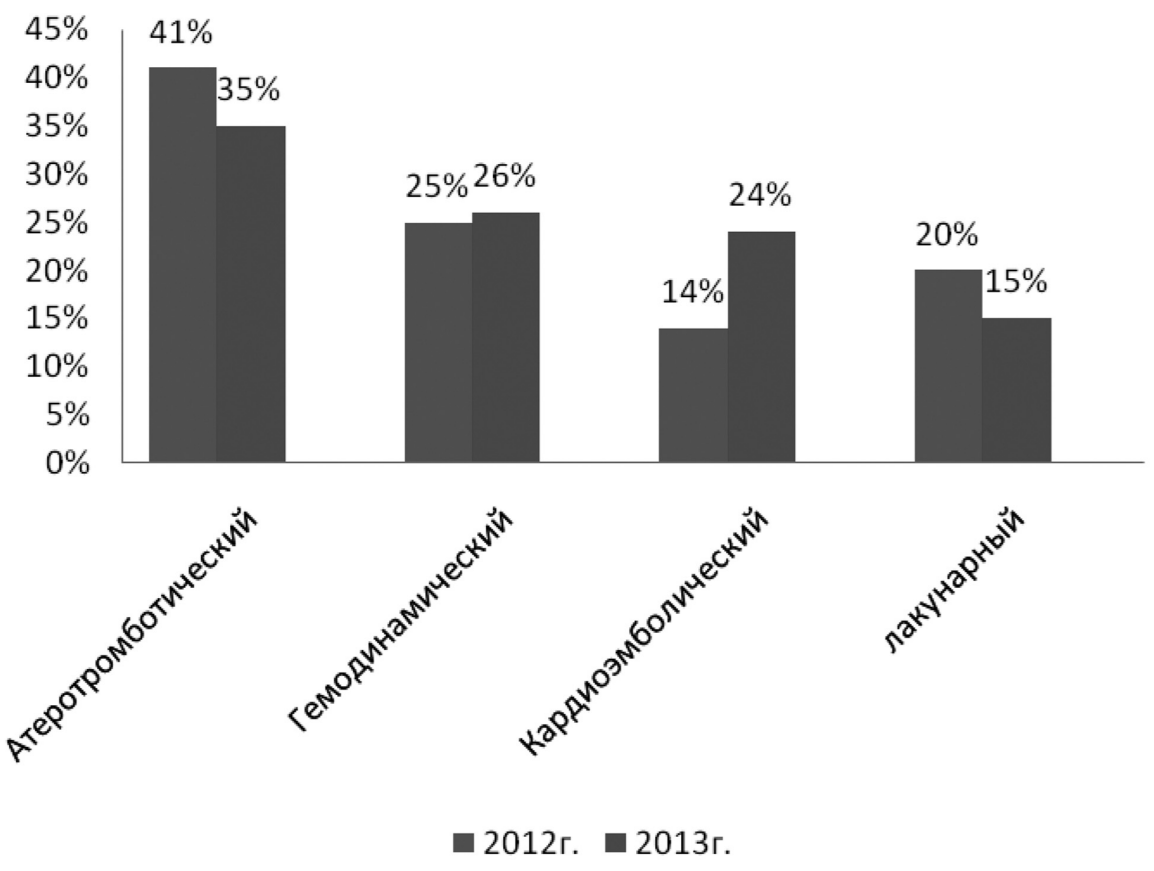

Рис. 6. Соотношение подтипов ишемического инсульта по данным госпитального регистра.

Выводы. Благодаря функционированию центра на базе областной больницы достигнута четкая маршрутизация пациентов по уровням оказания медицинской помощи больным с сосудистыми заболеваниями. Наметилась тенденция к снижению уровня летальности в регионе и уменьшению инвалидизации населения после перенесенного инсульта. Увеличилось количество больных госпитализиро- ванных в период "терапевтического окна".

Госпитальный этап оказания медицинской помощи больным с инсультом является определяющим в исходе заболевания.

Нарастающая угроза инсульта требует индивидуального подхода, основанного на современных методах диагностики доклинических проявлений наиболее опасных патологических процессов и синдромов. 


\section{ЛИТЕРАТУРА}

1. Государственная программа развития здравоохранения Республики Казахстан "Саламатты Казахстан" на 2011- 2015 гг

2. Суслина 3.А. Эпидемиологические аспекты изучения инсульта. Время подводить итоги. / 3.А. Суслина, Ю.Я. Варакин // Анналы клинической и экспериментальной неврологии - 2007 - Т. 1, № 2. - C. 22-28.

3. Каменова С.У. Основные принципы организации медицинской помощи больным инсультом.
Здоровье и болезнь.2012г., №2(104). С115-116

4. Каменова С.У., Ли Е.Ю., Мухамбетова К.И. Изучение распространенности мозгового инсульта в Западном регионе Казахстана // Медицина. 2007. - № 11 (65). - С. 54-56.

5. Каменова С.У., Ли Е.Ю., Маханбетжанова Р.А. и др. Эпидемиология мозгового инсульта в Казахстане // Всерос. науч.-практ. конф.: "Актуальные вопросы психиатрии и неврологии", (СанктПетербург, 18-19 октября 2007 г.). - 2007. - С.

\title{
SUMMARY
}

\section{THE ORGANIZATION OF CARE FOR PATIENTS WITH STROKE}

\author{
Kamenova S.U., Kondybayeva A.M., Ostapenko O.A., Belaya E. \\ KazNMU named by S.D.Asfendiyarov, Almaty
}

The analysis of the problem of the vascular diseases of the brain needs the estimation of the organization of help to sick people in early stages. The medical correction of the earliest vascular syndromes can be very effective and capable for the reducing of the cerebrovascular accidents, that's why we must have well-timed diagnostics and to render the skilled help. In this article were presented epidemiological dates of the cerebrovascular accident in Almaty and Atirau region.

Keywords: stroke, emergency, computed tomography, hospital stage, prevalence, mortality, lethality.

\section{XÜLASə}

\section{INSULTLU XəSTəLӘRə YARDIMIN TəŞKILI}

\author{
S.U.Kamenova, A.M.Kondıbayeva, O.A.Ostapenko, Y.Belaya \\ S.D.Asfendiyarov adına Kazax Milli Tibb Universiteti, Almaata
}

Beyin damar xəstəlikləri probleminin təhlili erkən mərhələlərdə xəstələrə yardımın təşkilinin qiymətləndirilməsini tələb edir. Așkar edilmiş erkən damar sindromlarının müalicəvi korreksiyası olduqca effektiv ola bilər, və vaxtında aparılan diaqnostika və ixtisaslandırılmış yardımın göstərilməsi insultla xəstələnmə səviyyəsinin əhəmiyyətli dərəcədə azalması ilə nəticələnə bilər. Məqalədə Almatı şəhəri və Atırau vilayəti üzrə epidemioloji göstəricilər verilmişdir.

Açar sözləri: insult, təcili yardım, kompyuter tomoqrafiyası, hospital mərhələsi, yayılma dərəcəsi, ölüm göstəricisi, letallıq.

Redaksiyaya daxil olub: 17.08.2013

Çapa tövsiya olunub: 16.09.2013

Rəyçi: Z.M.Sadıxova, t.ü.f.d., dosent 